Review

\title{
Molecular Modeling of PEGylated Peptides, Dendrimers, and Single-Walled Carbon Nanotubes for Biomedical Applications
}

\author{
Hwankyu Lee \\ Department of Chemical Engineering, Dankook University, Yongin 448-701, Korea; \\ E-Mail: leeh@dankook.ac.kr; Tel.: +82-31-8005-3569; Fax: +82-31-8021-7216
}

Received: 30 December 2013; in revised form: 24 February 2014 / Accepted: 28 February 2014 /

Published: 12 March 2014

\begin{abstract}
Polyethylene glycol (PEG) has been conjugated to many drugs or drug carriers to increase their solubility and circulating lifetime, and reduce toxicity. This has motivated many experimental studies to understand the effect of PEGylation on delivery efficiency. To complement the experimental findings and uncover the mechanism that cannot be captured by experiments, all-atom and coarse-grained molecular dynamics (MD) simulations have been performed. This has become possible, due to recent advances in simulation methodologies and computational power. Simulations of PEGylated peptides show that PEG chains wrap antimicrobial peptides and weaken their binding interactions with lipid bilayers. PEGylation also influences the helical stability and tertiary structure of coiled-coil peptides. PEGylated dendrimers and single-walled carbon nanotubes (SWNTs) were simulated, showing that the PEG size and grafting density significantly modulate the conformation and structure of the PEGylated complex, the interparticle aggregation, and the interaction with lipid bilayers. In particular, simulations predicted the structural transition between the dense core and dense shell of PEGylated dendrimers, the phase behavior of self-assembled complexes of lipids, PEGylated lipids, and SWNTs, which all favorably compared with experiments. Overall, these new findings indicate that simulations can now predict the experimentally observed structure and dynamics, as well as provide atomic-scale insights into the interactions of PEGylated complexes with other molecules.
\end{abstract}

Keywords: molecular dynamics simulation; PEGylation; antimicrobial peptide; coiled coil; dendrimer; carbon nanotube 


\section{Introduction}

Polyethylene oxide (PEO) and polyethylene glycol (PEG) are polymers with the formulas, respectively, $\mathrm{H}_{3} \mathrm{C}-\mathrm{O}-\left(\mathrm{CH}_{2}-\mathrm{CH}_{2}-\mathrm{O}\right)_{n}-\mathrm{CH}_{3}$ and $\mathrm{HO}-\left(\mathrm{CH}_{2}-\mathrm{CH}_{2}-\mathrm{O}\right)_{n}-\mathrm{H}$, which have been widely used to replace various membranes, solvents, and nanocomposites for chemical, biomedical, and manufacturing applications. In particular, they have low toxicity and high solubility in water. Also, they can sterically shield molecules encapsulated in drug carriers and thus have been covalently or noncovalently conjugated to a number of pharmaceuticals, a process called PEGylation [1,2]. These biomedical applications of PEGylation have been shown to reduce the cytotoxicity as well as increase the water solubility and circulating lifetime of drug molecules or drug carriers such as peptides [3,4], oligonucleotides [5-8], lipid liposomes [9-13], biodegradable hydrogels [14,15] and nanoparticles [16-19]. Although experiments have revealed vital information on the large-scale interactions of PEGs with drugs and drug carriers, many atomic-level questions that cannot be answered by experiments remain to be solved. For example, the conformational and structural characterization of PEGylated complexes and their effects on delivery efficiency are not always easy to be interpreted by experiments. On the other hand, atomic-level phenomena can be captured in detail by molecular dynamics (MD) simulations, which offer insights into structure and dynamics, assuming that these simulations can be validated by successful comparisons to available experiment results. In particular, recent advances in computer performance and simulation methodology have allowed the direct comparison of simulation results with experiments, as well as visualization of the mechanism on atomic scale.

Simulation studies have been performed for various PEGylated molecules such as proteins, lipids, drugs, nanomaterials, hydrogels, and block copolymers. Since this field is too broad to be fully covered in this review, we here consider only selective computational studies: PEGylated antimicrobial peptides (AMPs), coiled-coil peptides, dendrimers, and single-walled carbon nanotubes (SWNTs), which have been widely simulated but relatively less reviewed. In this review, we will first (Section 2) briefly review the parameterization of all-atom and coarse-grained (CG) force fields for PEO and PEG. Next (Section 3), MD simulations of PEGylated AMPs and coiled-coil peptides will be reviewed. Lastly (Sections 4 and 5), we will focus on simulations of PEGylated dendrimers and SWNTs.

\section{Development of All-Atom and Coarse-Grained PEO/PEG Force Fields}

Potential parameters, which typically consist of Lennard-Jones (LJ), electrostatic (coulomb), bond, angle, and torsional terms, have been developed for all-atom and coarse-grained (CG) PEO/PEG force fields. Quantum mechanics (QM) calculations were first performed and used for the development of all-atom models, which were again used to parameterize CG force fields. The details of potential parameters for each model are given in the references and will not be discussed in this review. Instead, the development history of some well-known PEG models will be briefly introduced.

The Smith group pioneered the development of the PEO/PEG model for the aqueous environment. The all-atom model for PEO was parameterized to reproduce relative free energies and conformer populations of 1,2-dimethoxyethane (DME) in water calculated from QM [20-23]. Their MD simulations captured the hydrogen bonding interaction between PEO and water, and predicted the conformational and structural properties of PEOs in water, in reasonable agreement with experiments [24,25]. Other 
groups also developed their own force fields and studied conformation and structure of short PEO and PEG chains [26-31]. Recently, MacKerell, Pastor, and coworkers developed the CHARMM ether force field (version C35) from the QM calculation [32], and then they corrected the torsional potential and released the revised version (C35r) [33]. With the CHARMM C35r force field, MD simulations of 9-mers, 18-mers, 27-mers, and 36-mers of PEOs and PEGs showed the persistence length $\lambda=3.7 \AA$, the radii of gyration $R_{g} \propto M_{\mathrm{w}}^{0.52 \pm 0.02}$ (ideal chain behavior for short chains), hydrodynamic radii calculated from diffusivities, and the shape anisotropy of 2.59:1.44:1.00 [33], in excellent agreement with the polymer theories and experiments. Stepniewski et al. also parameterized PEGs with the OPLS all-atom force field and simulated the bilayer composed of PEGylated lipids, showing the electrostatic interaction between ions and PEG oxygens, and the penetration of PEGs into the hydrophobic region of the lipid bilayer in the liquid phase [34].

Although these all-atom models can accurately predict the conformation and structure of PEGs and their interactions with other molecules, their system size and time scale are limited. To overcome this, CG PEG models have also been developed. Initially, the implicit solvent models were developed by the Smith group and others, which predicted the experimentally observed chain dimensions, aggregation number, and critical micelle concentration [35-37]. Although not computationally demanding, the application of implicit solvent models to multicomponent mixtures is limited. For example, the implicit model cannot be used for the simulation of the complex with other molecules such as lipids and proteins. The CG PEO model with explicit solvent was developed by Klein and co-workers, showing the self-assembly of diblock copolymers in explicit water, and the strong interaction with lipid bilayers [38-40]. Our group parameterized a PEO/PEG model within a framework of the "MARTINI" CG force field developed by Marrink et al. [41,42]. The MARTINI PEO/PEG model predicted the size, diffusivities, hydrodynamics, end-to-end distances, and the distributions of bond lengths, angles, and dihedrals, all of which were close to those from all-atom simulations and experiments [43]. In Figure 1, mixtures of lipids and PEGylated lipids in water self-assemble to liposomes, bicelles, and micelles at the expected ratios of lipids and PEGylated lipids [44,45], showing that the aggregate size decreases with increasing PEGylated-lipid concentration, in qualitative agreement with experiment. Recently, this CG model was reparameterized by the Monticelli group, which has an increased time step, while maintaining the accurate prediction of PEG conformation [46]. Unlike other CG models, the CG model of mapping two monomers onto one bead was also developed [47].

Figure 1. Snapshots at the beginning ( $0 \mathrm{~ns}$, left) and end (300 ns, columns 2, 3, 4, 5, and 6) of simulations with 0-99 mol \% PEGylated lipids. Initial configuration is shown only for a simulation with $0 \mathrm{~mol} \%$, but this random configuration is applied for initial configurations of all other simulations. Blue, green, and light blue dots respectively represent head groups, glycerols, and tail groups of the lipid, and red dots represent PEG chains. (Reprinted with permission from [44]. Copyright 2013 American Chemical Society).

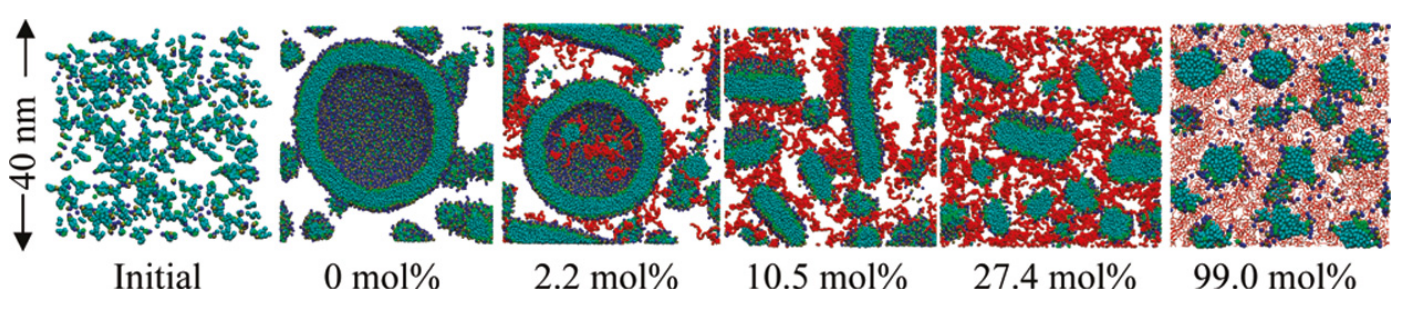




\section{Simulations of PEGylated Peptides}

\subsection{Antimicrobial Peptides}

AMPs are short ( $<50$ amino acids), cationic, and amphipathic peptides that can be extracted from eukaryotic organisms such as plants, insects, and vertebrates [48]. Since cationic AMPs tend to interact electrostatically with anionic bacterial membranes rather than neutral animal membranes, they have been considered to be promising candidates for novel antibiotics $[49,50]$. To achieve this biomedical application, a high concentration of AMPs is required, but at high concentration they can also attack the human cell, indicating reduced specific targeting. To overcome this limitation, PEGylation has been applied to AMPs. Experimentally, nisin [51], magainin 2, and tachyplesin I [3,4] were PEGylated, showing increased solubility and decreased antimicrobial activity. In particular, the Matsuzaki group found that the decrease in antimicrobial activity was larger in $\beta$-sheet tachyplesin I than in $\alpha$-helical magainin, showing the dependence on the peptide structure $[3,4]$. Most simulations and theoretical studies have focused on the secondary structure of AMPs and their interactions with lipid bilayers such as the formation of toroidal pores [52-54]. Here, simulations of PEGylated AMPs only will be reviewed.

Wu et al. performed all-atom simulations of cecropin P1 linked to the silica surface via a PEO chain, showing conformation of immobilized AMPs and their interactions with the silica surface [55]. Recently, our group simulated PEGylated magainin 2 and tachyplesin I interacting with lipid bilayers [56]. First, AMPs were simulated in water, showing that PEG chains wrap both magainin 2 and tachyplesin I. The $\alpha$-helix of PEGylated magainin 2 was broken, while the $\beta$-sheet of PEGylated tachyplesin I remains stable, in agreement with experiments. Simulations of unPEGylated and PEGylated AMPs in lipid bilayers showed that PEGylation inhibits the electrostatic interaction between peptides and lipid head groups. Interestingly, this PEGylation effect was more significant for magainin 2 than for tachyplesin I because the random-coiled magainin 2 are more completely covered by PEG chains and thus cannot interact with the bilayer surface as much as tachyplesin I do (Figure 2), which qualitatively support Matsuzaki's experiments.

Figure 2. Snapshots of PEGylated magainin 2 (left) and tachyplesin I (right) binding to the bilayer surface. PEG chains, peptide backbones, and cationic residues of the peptide are colored in red, gray, and blue, respectively. (Reprinted with permission from [56]. Copyright 2013 American Chemical Society).

\section{PEGylated magainin 2 PEGylated tachyplesin I}

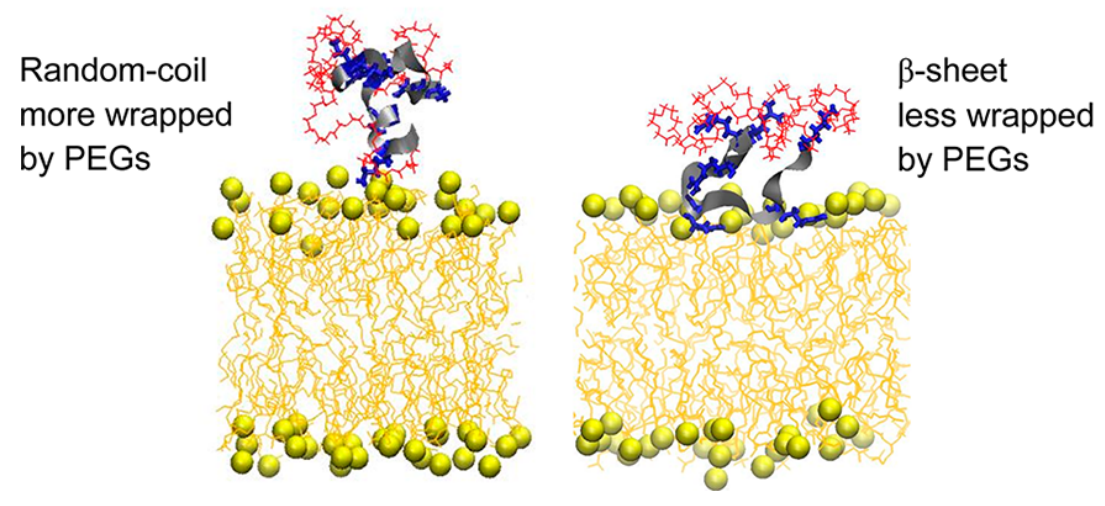




\subsection{Coiled-Coil Peptides}

Coiled coils consist of two or more $\alpha$-helices wound into a superhelix with a large pitch. The coiled-coil sequences contain a heptad repeat of seven amino acid residues, where hydrophobic residues are located in the core of coiled-coil helix bundles [57]. Since these coiled coils can self-assemble into protein fibers, synthetic coiled coils have been designed and used as scaffolds in 3D cell culture engineering, as templates for the assembly of other polymer and nanoparticle materials, and as protein building blocks [58-61]. To increase their solubility and structural stability, coiled coils have been conjugated with PEGs. Experimentally, the Klok group [62-66], the Kros group [67-71], and the $\mathrm{Xu}$ group [72-76] synthesized PEGylated coiled coils, characterized their conformation and structure, and investigated the effect of PEGylation on the self-assembled structures and the interactions with other molecules. Computationally, the sequenced-based programs were developed to predict the existence and structure of coiled coils [77-83], and MD simulations were performed to study the stability of coiled coils [84-93].

Jain and Ashbaugh performed replica exchange MD (REMD) simulations of PEGylated coiled coils [94]. PEG chains (20 and 40 monomers of EO; C-O-C) were conjugated to the $N$-terminal group of the lysine-rich peptide $1 \mathrm{CW}$ (pdb: 1COI, the peptide experimentally studied by the Xu group), the neutralized $1 \mathrm{CW}$, and the polyalanine peptide. Figure 3 compares the fractional helicity of unPEGylated and PEGylated peptides as a function of temperature, indicating that larger PEG chains induce higher helicity of peptides, in quantitative agreement with experiments. Also, simulations showed that PEG chains have electrostatic interaction with cationic lysine residues of the peptide, which stabilizes the helical structure of each peptide but still does not influence the tertiary structure of the coiled coil.

Figure 3. Helix melting curves of the pure peptide $(1 \mathrm{CW})$ and its conjugates with 20- and 40-mers of ethylene oxide (EO). (Reprinted with permission from [94]. Copyright 2013 American Chemical Society).

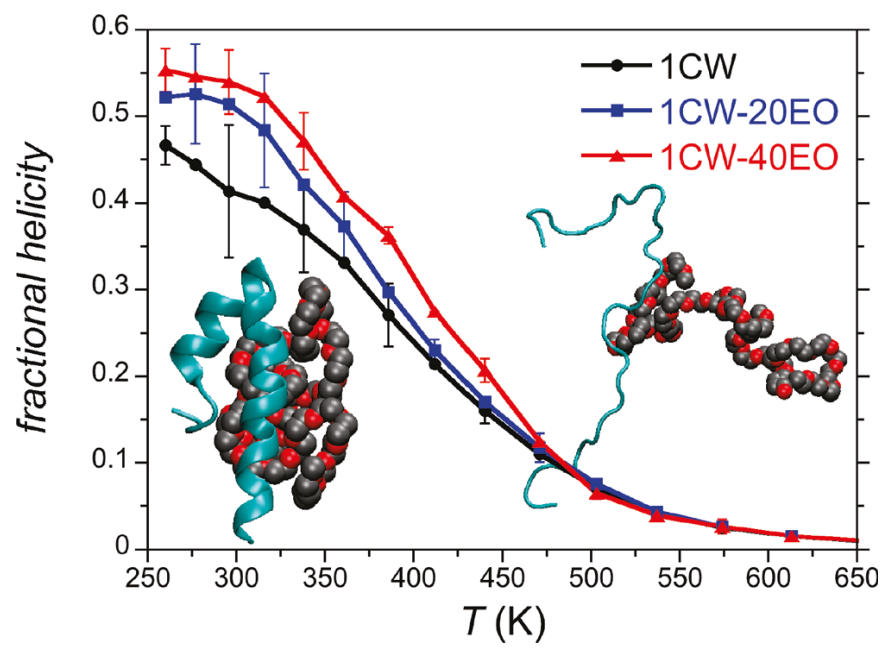

Hamed et al. performed all-atom and CG simulations of the same $\alpha$-helical peptide (pdb: 1COI) grafted with the PEG chain [95]. Figure 4 shows that the PEG chain with a larger end-to-end distance induces an increase in the solvent accessible surface area (SASA) of the peptide, which makes the 
backbone hydrogen bonds more accessible to water molecules, leading to the lower helicity of the peptide. This indicates that peptide helicity is modulated by the SASA that depends on the PEG conformation and the PEG-peptide interaction. They also found that peptides interact with PEG chains because of the electrostatic interaction between cationic lysines and PEG oxygens as well as the interaction of hydrophobic amino acids with PEGs rather than with water.

Figure 4. (a) Schematic of constant force pulling simulations, where the external force applies to the PEG chain $\left(M_{\mathrm{w}}=882\right)$; and (b) the peptide helicity and solvent accessible surface area (SASA) as a function of the end-to-end distance of the grafted PEG. (Reprinted with permission from [95]. Copyright 2013 American Chemical Society).

(a)

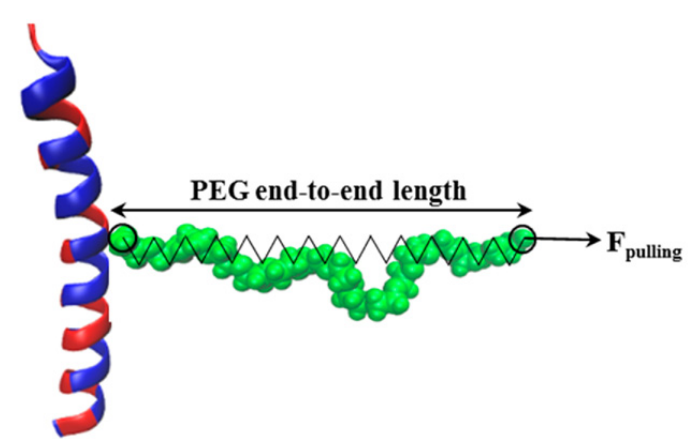

(b)

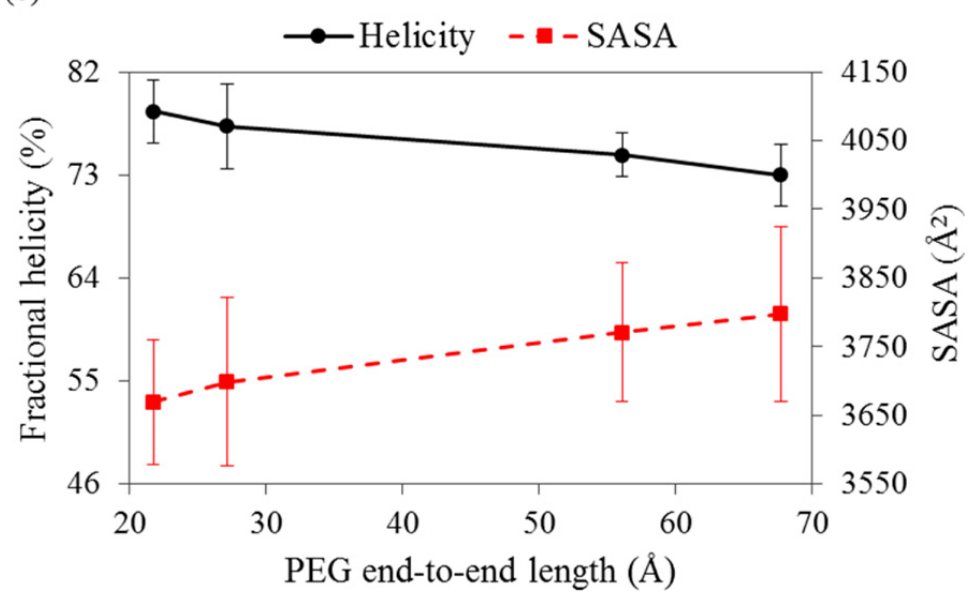

Besides these coiled coils, the self-assemblies of cyclic peptides grafted with PEG chains were recently simulated by Ruiz and Keten [96]. They calculated the binding free energies for a cyclic peptide dimer with and without PEGs, showing that the binding energy between peptides is modulated by the PEG length and grafting density. Their findings also agree with theories and experimental observations that showed the entropic penalty induced by the conformational transition of the conjugated PEG chains in assembled nanotubes.

\section{Simulations of PEGylated Dendrimers}

Polyamidoamine (PAMAM) dendrimers, which consist of a central core, regularly branched monomeric building blocks, and many surface terminal groups, are among the best candidate nanoparticles for use as antitumor therapeutics to detect and target tumor cells because of their controlled mass, surface valency, and surface functionality [97]. The conformation and structure of 
PAMAM dendrimers and their interactions with conjugate molecules (DNA, peptides, and polymers) and lipid bilayers have been widely studied through experiments and simulations [98-129]. Here, the simulation studies on PEGylated dendrimers are reviewed.

Tanis and Karatasos performed all-atom MD simulations of a dendrimer grafted with a single PEO chain and predicted the complex conformation and the extent of the hydrogen bonds between dendrimer and PEO at various $\mathrm{pH}$ values [130]. Our group performed CG MD simulations of PEGylated dendrimers, showing the inhibition effect of PEG chains on the interparticle aggregation in water [131] and on the dendrimer-induced pore formation in lipid bilayers [132]. In particular, we simulated generations 3, 4, and 5 dendrimers grafted with PEGs of different sizes $\left(M_{\mathrm{w}}=550\right.$ and 5000) and grafting densities (12\%-94\% of surface terminals), showing that longer PEG chains with higher grafting density yield PEG-PEG crowding, which stretches dendrimer terminals towards water, leading to a larger size and a dense-shell structure of the dendrimer [133], as shown in Figure 5. Also, simulations showed that long PEG5000 chains at high grafting density self-penetrate into the attached dendrimer, occupying the dendrimer's vacant interior that would otherwise be available for encapsulating hydrophobic compounds, implying that the encapsulation efficiency of dendrimers can be modulated by the PEG length and grafting density.

Figure 5. Snapshots of G4 dendrimers attached with 8 PEG5000 (left) and 32 PEG5000 (right) at the end of simulations, leading to dense-core and dense-shell structures, respectively. Black and red colors represent dendrimers and PEG chains, respectively. (Reprinted with permission from [133]. Copyright 2013 American Chemical Society).

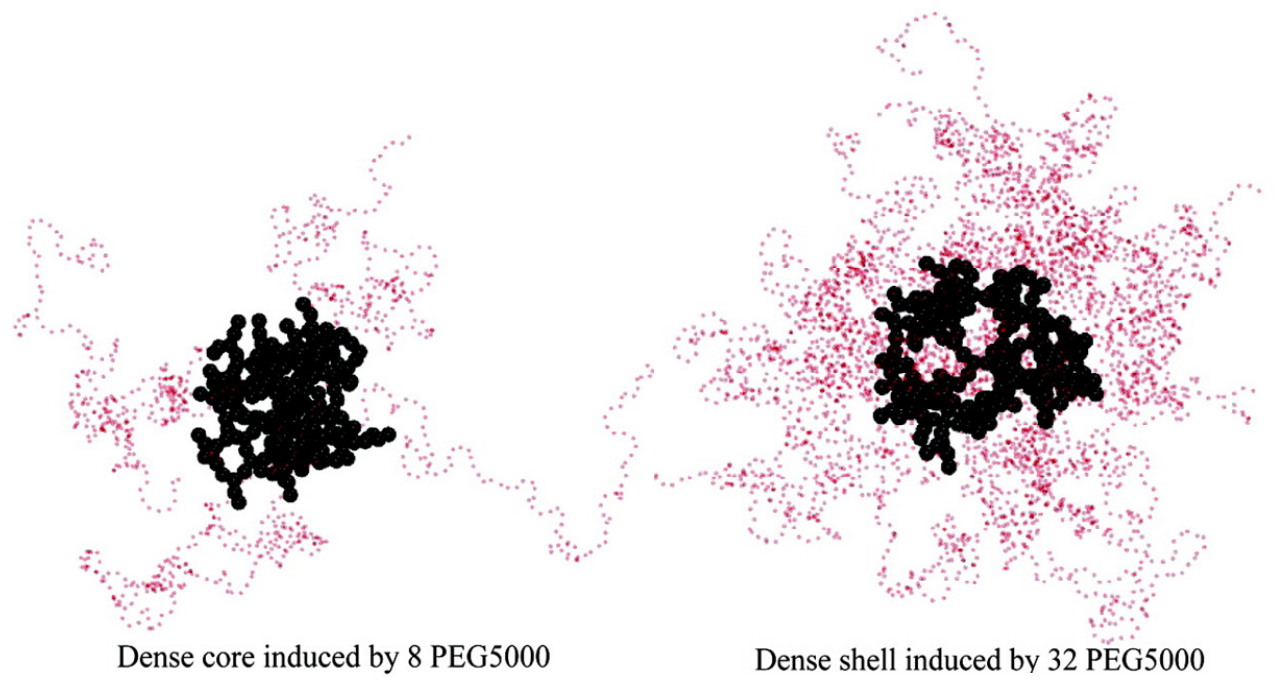

Albertazzi et al. synthesized hybrid dendrimers with PEG cores [134], which are different from other PEGylated dendrimers that typically have PEG chains grafted onto outer terminal groups. Their experiments showed that the extent of cellular uptake and transfection is modulated by the complex structure and the topology of the PEG core. These results were supported by their MD simulations of dendrimers with 2-arm PEG cores and 4-arm PEG cores, which showed that the dendrimers with more PEG cores have a much more swollen conformation, as shown in Figure 6. 
Figure 6. Snapshots of molecular dynamics (MD) simulations of dendrimers grafted with (a) 2-arm PEG cores and (b) 4-arm PEG cores. (Reprinted with permission from [134]. Copyright 2013 American Chemical Society).

a

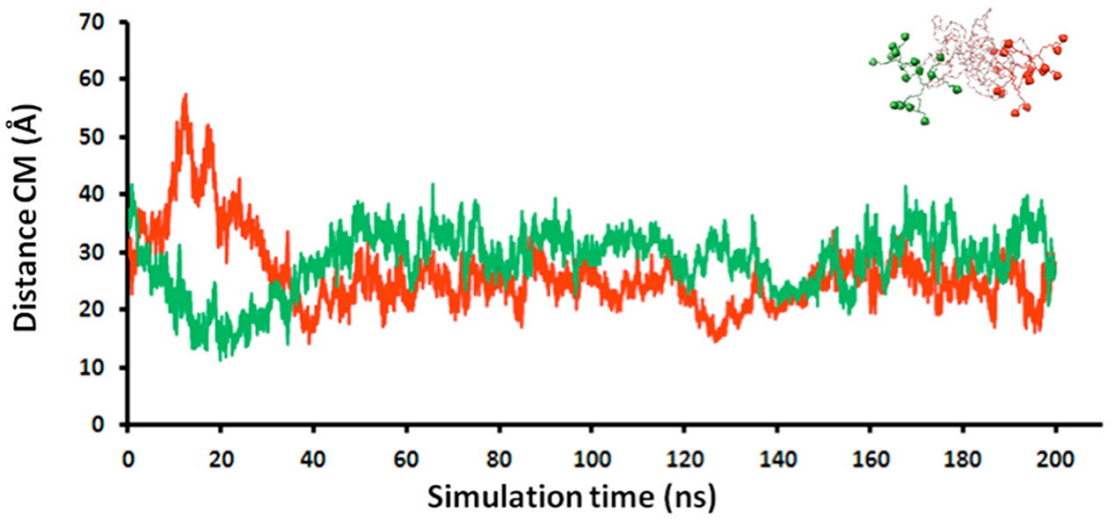

b

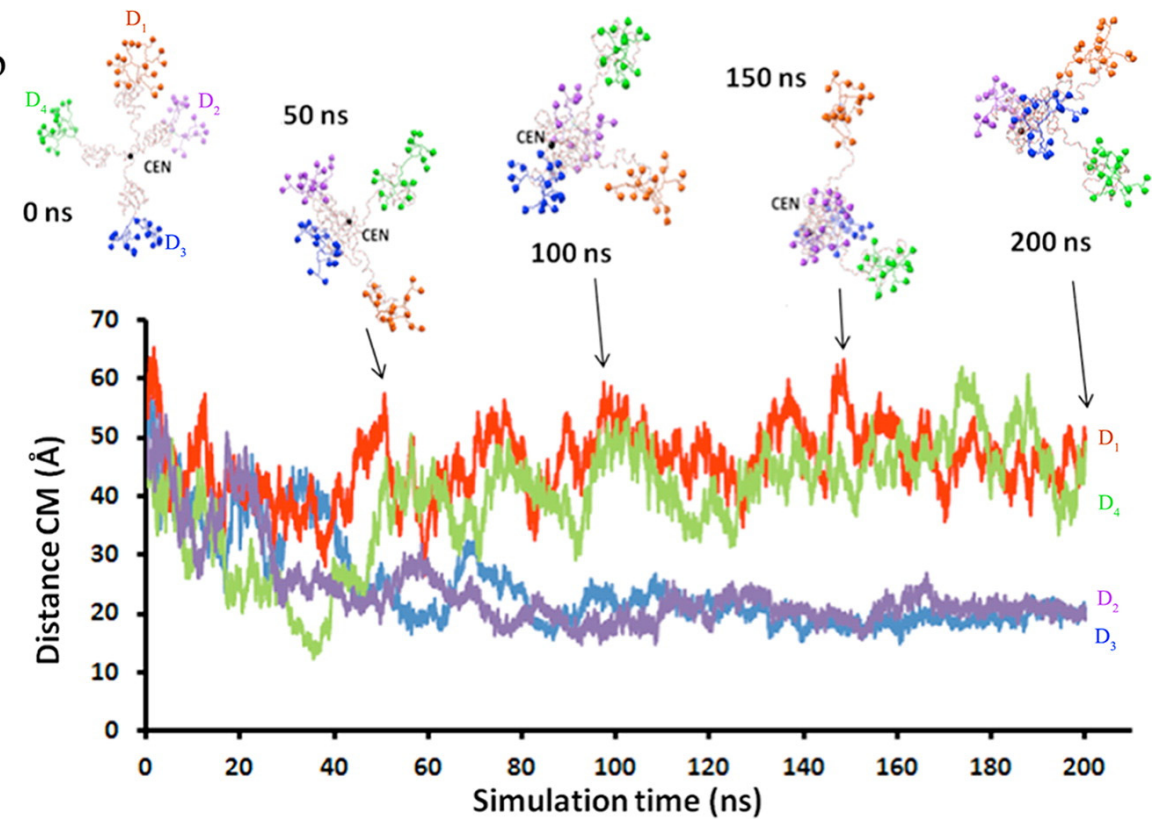

Recently, Karatasos simulated PEGylated hyperbranched polyesters with doxorubicin (a hydrophobic anti-cancer drug) [135]. Figure 7 shows that PEGylated polyesters form a complex with doxorubicin via their hydrogen bonding interactions. These hydrogen bonding interactions were modulated by the charge density of doxorubicin and the size of PEG chains, indicating the dependence on drug electrostatics and PEG conformation.

Pavan et al. performed well-tempered metadynamics simulations of PEGylated dendrimers in water to obtain enough samples by overcoming energy barriers [136]. Radii of gyration and hydrodynamic radii of PEGylated dendrimers were calculated, in excellent agreement with those measured from their dynamic light scattering (DLS) experiments. The free energy surface of PEGylated dendrimers in water indicated that PEGylated dendrimers have a tight globular shape rather than an open configuration. They also found that larger PEGs induce a higher extent of crowding, leading to aggregation of the dendrimer-PEG complex. 
Figure 7. Snapshots of the complex of PEGylated hyperbranched polyesters and doxorubicin. Doxorubicins are represented as differently colored sticks. The PEGylated polyesters are depicted in ball and stick form. The ions $\mathrm{Na}^{+}$and $\mathrm{Cl}^{-}$are shown as red and green beads, respectively. (Reprinted with permission from [135]. Copyright 2013 American Chemical Society).

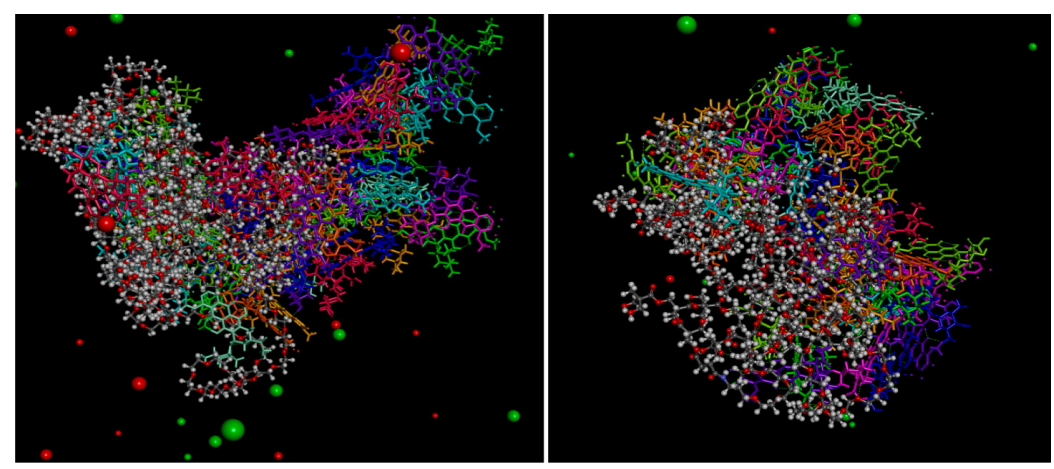

\section{Simulations of PEGylated Carbon Nanotubes}

SWNTs have been considered to be promising nanomaterials for use as antitumor therapeutics and drug or gene transporters because of their excellent mechanical strength and chemical stability [137-139]. However, SWNTs are highly hydrophobic and thus aggregate in aqueous environment, which limits their biomedical applications in vivo. To overcome this, SWNTs have been covalently conjugated with PEG chains or noncovalently assembled with PEGylated lipids or surfactants. Experiments have shown (or proposed) the self-assembled structures of the SWNT-PEG complex, the conformation of the grafted PEG chains, the effect of PEGylation on SWNT aggregation, and the interaction of PEGylated SWNTs with lipid bilayers [140-149], which have motivated simulation studies.

Computational studies have mainly focused on the self-assembly of SWNTs and surfactants (or lipids) [143,150-154], and the interaction between SWNTs and lipid bilayers [155-168]. Simulations have shown that the self-assembly of SWNTs and their interactions with lipid bilayers can be modulated by the structure and concentration of surfactant, and the size and chirality of SWNT. To simulate PEGylated SWNTs and their interactions with lipid bilayers, our group recently parameterized CG SWNT and its interaction with CG PEG within a framework of the MARTINI force field [169]. We simulated the mixtures of SWNTs and lipids (or PEGylated lipids), which visualized the experimentally observed (or proposed) structures of the self-assembled SWNT-lipid complex. In Figure 8, lysophospholipids (single tail per lipid), phospholipids (double tails per lipid), and PEGylated phospholipids adsorb onto SWNTs in different conformations as "helical half-cylinders", "cylindrical micelles", and "hemimicelles (or random-adsorption)", respectively. These simulation findings indicate the dependence on the size of the lipid headgroup and tail, indicating the effects of lipid types and PEGylation, implying important roles of PEGylation and lipid types on the self-assembled structure and mechanism, which favorably compared with experimental findings. 
Figure 8. Snapshots at the end (500 ns) of simulations of single-walled carbon nanotubes (SWNTs) adsorbed onto lysophospholipids (1st row), phospholipids (2nd row), and PEGylated phospholipids (3rd and 4th rows). A cross section of the lipid-SWNT complex (left image) and a whole section of the SWNT with the ending (the last carbon). Coarse-grained (CG) beads of the lipid tail are depicted. Black, blue, and red colors respectively represent SWNTs, lipid tails, and PEG chains. (Reprinted with permission from [169]. Copyright 2013 American Chemical Society).

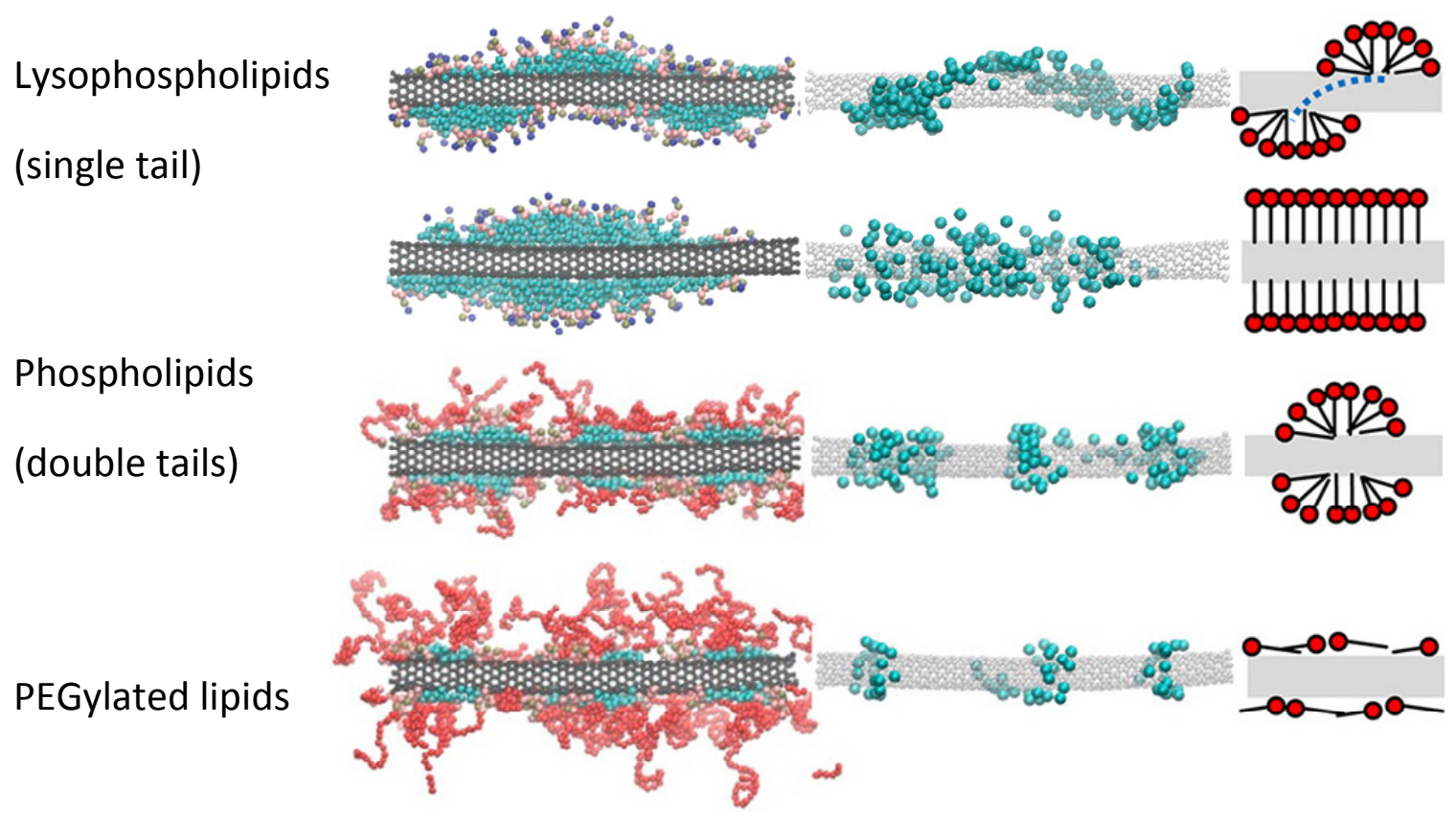

To understand the effects of PEGylation on interparticle aggregation, we also simulated multiple copies of the SWNT-lipid complex in water [170]. Figure 9 shows that all pure SWNTs aggregate, lipid-wrapped SWNTs partially aggregate, but PEGylated lipid-wrapped SWNTs completely disperse, indicating that short PEG chains $\left(M_{\mathrm{w}}=550\right)$ can inhibit interparticle aggregation, in agreement with experiment.

Figure 9. Snapshots at the beginning (0 ns, left) and end (500 ns, columns 2-4) of the simulations of three copies of the SWNT-lipid complex in water. Initial configuration is shown only for the system without lipids. (Reprinted with permission from [170]. Copyright 2013 American Chemical Society).

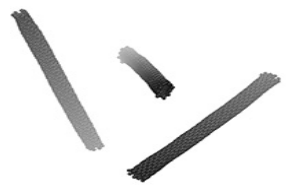

Initial

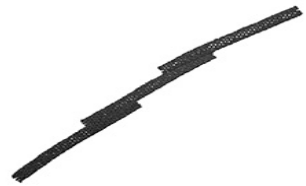

Pure SWNTs
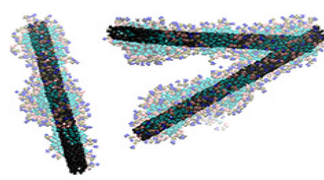

Lysophospholipidwrapped SWNTs

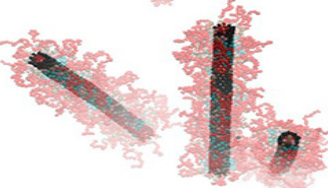

PEGylated lipid-wrapped SWNTs

The interactions between SWNTs and lipid bilayers were also investigated [170,171]. Un-PEGylated SWNTs insert into the lipid bilayer at the beginning of the simulation because of the hydrophobic interaction with the bilayer tails, while PEGylated SWNTs do not for the whole 
simulation time, indicating that long hydrophilic PEG chains can weaken the hydrophobic interaction and inhibit SWNT insertion (Figure 10). For unPEGylated SWNTs, the inserted SWNT beads are surrounded by entire tails of neighboring lipids in one leaflet of the bilayer, which induces positive curvature along the SWNT. This indicates that the insertion of SWNT into the bilayer and membrane curvature can be modulated by PEGylation. Our simulations also found that the PEGylation method influences the distribution of PEG chains along the SWNT, and that PEG size and grafting density modulate the conformation of PEG chains on SWNTs [172], which supports the experimentally proposed conformation of PEGs [173] and compares favorably with the mushroom-brush transition of the Alexander-de Gennes theory [174].

Figure 10. Snapshots of simulations of the lipid bilayer and the SWNT wrapped with PEGylated and unPEGylated lipids (respectively, left and right). The cross section of SWNT shows positive curvature in the lipid bilayer (upper right). (Reprinted with permission from [170]. Copyright 2013 American Chemical Society).

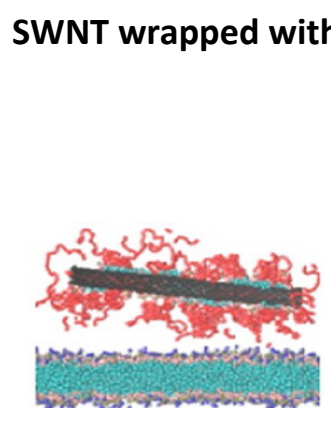

$500 \mathrm{~ns}$
SWNT wrapped with lipids

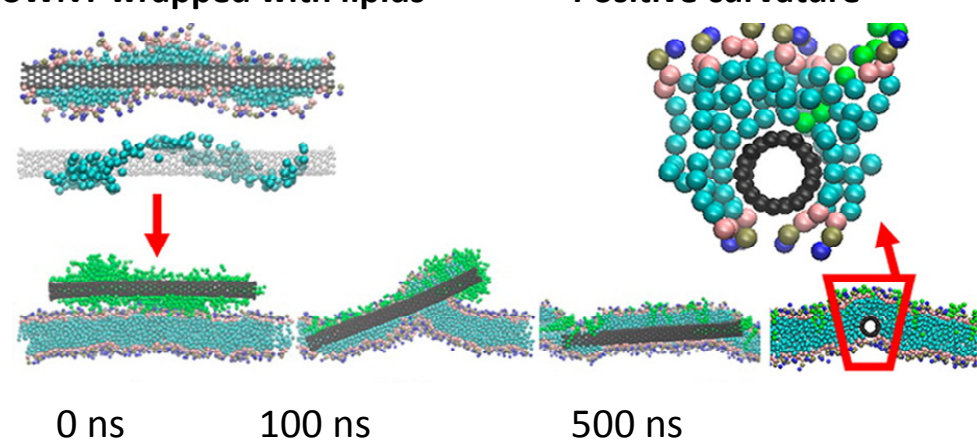

Recently, Crescenzo et al. performed all-atom MD simulations of SWNTs grafted with PEGs (homopolymer) and PEG-propylene sulfide (PEG-PPS; block copolymer), and compared the extent of covering the SWNT surface, showing that PEG-PPS more tightly wrap SWNTs than pure PEG do [175]. Aslan et al. simulated the self-assembly of PEGylated lipids and either an isolated or bundled SWNT, showing different density profiles of PEGs and their effects on antimicrobial activity [176]. Skandani and Al-Haik performed all-atom MD simulations of unPEGylated and PEGylated SWNTs with different diameters and chiralities in lipid bilayers [177]. Simulations showed that PEGylated SWNTs penetrated into the lipid bilayer slower than unPEGylated SWNTs. Also, penetration of the PEGylated SWNT showed a less energy-dependent mechanism, indicating lower adhesion energy, which favorably compared with their previous experiments [178].

\section{Conclusions}

Recent advances in simulation methodologies and computational power have made it possible to accurately predict conformation and dynamics. The all-atom models for PEO and PEG have been parameterized to reproduce free energies and conformer populations calculated from quantum chemistry calculations, which were again used to parameterize CG models. Initially, implicit solvent models were developed, but the explicit solvent models have become more popular, since they can be easily applied to multicomponent mixtures. All-atom and CG models predicted the conformation, 
hydrodynamics, and shape anisotropy of PEO and PEG, in excellent agreement with experiments and polymer theories. In particular, the CG models have been applied to large-scale systems such as the self-assembly of PEG and other molecules, and the interaction with lipid bilayers.

MD simulations have revealed much useful information about the structure and dynamics of PEGylated molecules. Since PEG chains are hydrophilic, they have been shown to have either attractive interactions with charged or hydrophilic molecules or repulsive interactions with highly hydrophobic molecules. For example, antimicrobial peptides, which consist of cationic amino acids, are wrapped by PEG chains. Also, PEG chains adsorb onto coiled coils that form helix bundles because of the core packing with hydrophobic residues and the electrostatic interaction between charged residues. All-atom simulations showed that the stability of secondary and tertiary structures of these peptides is modulated by PEGylation, implying the possible application of PEGylation into the peptide-based drugs and nanofibers. PEGylated nanoparticles such as dendrimers and SWNTs have also been computationally studied. Simulations of PEGylated dendrimers showed that the PEG size and grafting density influence the size, shape, and structural transition between the dense core and dense shell. Also, PEGylation inhibits the interparticle aggregation of dendrimers and weakens the interaction between dendrimers and lipid bilayers. For PEGylated lipids, CG simulations captured the self-assembled liposomes, bicelles, and micelles at the expected ratios of lipids and PEGylated lipids. The conformations of PEG chains grafted onto SWNTs, and the structures of the self-assembled SWNT-lipid (or PEGylated lipid) complex, the effects of PEGylation on interparticle aggregation and the interaction with lipid bilayers were favorably compared with polymer theories and experiments.

As reviewed above, all-atom and CG MD simulations have successfully matched experimentally measured properties and have provided atomic-scale insights into the structure and dynamics of PEG and its interactions with other molecules. However, more computational studies are still needed to complement or explain experimental observations. For example, different mechanisms for the penetration of polymers and nanoparticles into cell membranes have been proposed but are still not well understood. Also, simulations with ions have always been challenging due to force-field issues. For peptide simulation, the secondary structure and folding state need to be more accurately predicted within the limited simulation timescale. To resolve this in the future, advances in force field and simulation methodology should be attempted. This information from simulations can help in optimizing the size and grafting density of PEG chains to increase drug-delivery efficiency for applications in nanomedicine.

\section{Acknowledgments}

This research was supported by Basic Science Research Program through the National Research Foundation of Korea (NRF) funded by the Ministry of Education, Science and Technology (2012R1A1A1001196).

\section{Conflicts of Interest}

The authors declare no conflict of interest. 


\section{References}

1. Harris, J.M.; Martin, N.E.; Modi, M. PEGylation-A novel process for modifying pharmacokinetics. Clin. Pharmacokinet. 2001, 40, 539-551.

2. Harris, J.M.; Chess, R.B. Effect of PEGylation on pharmaceuticals. Nat. Rev. Drug Discov. 2003, 2, 214-221.

3. Imura, Y.; Nishida, M.; Ogawa, Y.; Takakura, Y.; Matsuzaki, K. Action mechanism of tachyplesin i and effects of PEGylation. Biochim. Biophys. Acta 2007, 1768, 1160-1169.

4. Imura, Y.; Nishida, M.; Matsuzaki, K. Action mechanism of PEGylated magainin 2 analogue peptide. Biochim. Biophys. Acta 2007, 1768, 2578-2585.

5. Jaschke, A.; Furste, J.P.; Nordhoff, E.; Hillenkamp, F.; Cech, D.; Erdmann, V.A. Synthesis and properties of oligodeoxyribonucleotide polyethylene-glycol conjugates. Nucleic Acids Res. 1994, $22,4810-4817$.

6. Jones, D.S.; Hachmann, J.P.; Osgood, S.A.; Hayag, M.S.; Barstad, P.A.; Iverson, G.M.; Coutts, S.M. Conjugates of double-stranded oligonucleotides with poly(ethylene glycol) and keyhole limpet hemocyanin-A model for treating systemic lupus-erythematosus. Bioconj. Chem. 1994, 5, 390-399.

7. Kabanov, A.V.; Vinogradov, S.V.; Suzdaltseva, Y.G.; Alakhov, V.Y. Water-soluble block polycations as carriers for oligonucleotide delivery. Bioconj. Chem. 1995, 6, 639-643.

8. Wang, S.; Lee, R.J.; Cauchon, G.; Gorenstein, D.G.; Low, P.S. Delivery of antisense oligodeoxyribonucleotides against the human epidermal growth-factor receptor into cultured $\mathrm{kb}$ cells with liposomes conjugated to folate via polyethylene-glycol. Proc. Natl. Acad. Sci. USA 1995, 92, 3318-3322.

9. Allen, T.M.; Hansen, C.; Martin, F.; Redemann, C.; Yauyoung, A. Liposomes containing synthetic lipid derivatives of poly(ethylene glycol) show prolonged circulation half-lives in vivo. Biochim. Biophys. Acta 1991, 1066, 29-36.

10. Allen, T.M.; Hansen, C. Pharmacokinetics of stealth versus conventional liposomes_Effect of dose. Biochim. Biophys. Acta 1991, 1068, 133-141.

11. Papahadjopoulos, D.; Allen, T.M.; Gabizon, A.; Mayhew, E.; Matthay, K.; Huang, S.K.; Lee, K.D.; Woodle, M.C.; Lasic, D.D.; Redemann, C.; et al. Sterically stabilized liposomes-Improvements in pharmacokinetics and antitumor therapeutic efficacy. Proc. Natl. Acad. Sci. USA 1991, 88, 11460-11464.

12. Klibanov, A.L.; Maruyama, K.; Torchilin, V.P.; Huang, L. Amphipathic polyethyleneglycols effectively prolong the circulation time of liposomes. FEBS Lett. 1990, 268, 235-237.

13. Torchilin, V.P.; Klibanov, A.L.; Huang, L.; Odonnell, S.; Nossiff, N.D.; Khaw, B.A. Targeted accumulation of polyethylene glycol-coated immunoliposomes in infarcted rabbit myocardium. FASEB J. 1992, 6, 2716-2719.

14. Sawhney, A.S.; Pathak, C.P.; Hubbell, J.A. Bioerodible hydrogels based on photopolymerized poly(ethylene glycol)-co-poly( $\alpha$-hydroxy acid) diacrylate macromers. Macromolecules 1993, 26, 581-587.

15. Burdick, J.A.; Anseth, K.S. Photoencapsulation of osteoblasts in injectable rgd-modified PEG hydrogels for bone tissue engineering. Biomaterials 2002, 23, 4315-4323. 
16. Kim, Y.; Klutz, A.M.; Jacobson, K.A. Systematic investigation of polyamidoamine dendrimers surface-modified with poly(ethylene glycol) for drug delivery applications: Synthesis, characterization, and evaluation of cytotoxicity. Bioconj. Chem. 2008, 19, 1660-1672.

17. Kojima, C.; Kono, K.; Maruyama, K.; Takagishi, T. Synthesis of polyamidoamine dendrimers having poly(ethylene glycol) grafts and their ability to encapsulate anticancer drugs. Bioconj. Chem. 2000, 11, 910-917.

18. Luo, D.; Haverstick, K.; Belcheva, N.; Han, E.; Saltzman, W.M. Poly(ethylene glycol)-conjugated pamam dendrimer for biocompatible, high-efficiency DNA delivery. Macromolecules 2002, 35, 3456-3462.

19. Chun, D.; Wudl, F.; Nelson, A. Supramacromolecular assembly driven by complementary molecular recognition. Macromolecules 2007, 40, 1782-1785.

20. Bedrov, D.; Borodin, O.; Smith, G.D. Molecular dynamics simulations of 1,2-dimethoxyethane/water solutions: 1. Conformational and structural properties. J. Phys. Chem. B 1998, 102, 5683-5690.

21. Smith, G.D.; Bedrov, D.; Borodin, O. Molecular dynamics simulation study of hydrogen bonding in aqueous poly(ethylene oxide) solutions. Phys. Rev. Lett. 2000, 85, 5583-5586.

22. Bedrov, D.; Pekny, M.; Smith, G.D. Quantum-chemistry-based force field for 1,2-dimethoxyethane and poly(ethylene oxide) in aqueous solution. J. Phys. Chem. B 1998, 102, 996-1001.

23. Smith, G.D.; Yoon, D.Y.; Jaffe, R.L.; Colby, R.H.; Krishnamoorti, R.; Fetters, L.J. Conformations and structures of poly(oxyethylene) melts from molecular dynamics simulations and small-angle neutron scattering experiments. Macromolecules 1996, 29, 3462-3469.

24. Smith, G.D.; Borodin, O.; Bedrov, D. A revised quantum chemistry-based potential for poly(ethylene oxide) and its oligomers in aqueous solution. J. Comput. Chem. 2002, 23, $1480-1488$.

25. Smith, G.D.; Bedrov, D.; Borodin, O. Conformations and chain dimensions of poly(ethylene oxide) in aqueous solution: A molecular dynamics simulation study. J. Am. Chem. Soc. 2000, 122, 9548-9549.

26. Dong, H.; Hyun, J.K.; Durham, C.; Wheeler, R.A. Molecular dynamics simulations and structural comparisons of amorphous poly(ethylene oxide) and poly(ethylenimine) models. Polymer 2001, 42, 7809-7817.

27. Fischer, J.; Paschek, D.; Geiger, A.; Sadowski, G. Modeling of aqueous poly(oxyethylene) solutions: 1. Atomistic simulations. J. Phys. Chem. B 2008, 112, 2388-2398.

28. Tritopoulou, E.A.; Economou, I.G. Molecular simulation of structure and thermodynamic properties of pure tri- and tetra-ethylene glycols and their aqueous mixtures. Fluid Phase Equilib. 2006, 248, 134-146.

29. Winger, M.; de Vries, A.H.; van Gunsteren, W.F. Force-field dependence of the conformational properties of $\alpha, \omega$-dimethoxypolyethylene glycol. Mol. Phys. 2009, 107, 1313-1321.

30. Neyertz, S.; Brown, D.; Thomas, J.O. Molecular dynamics simulation of crystalline poly(ethylene oxide). J. Chem. Phys. 1994, 101, 10064-10073.

31. Lin, B.; Boinske, P.T.; Halley, J.W. A molecular dynamics model of the amorphous regions of polyethylene oxide. J. Chem. Phys. 1996, 105, 1668-1681. 
32. Vorobyov, I.; Anisimov, V.M.; Greene, S.; Venable, R.M.; Moser, A.; Pastor, R.W.; MacKerell, A.D. Additive and classical drude polarizable force fields for linear and cyclic ethers. J. Chem. Theory Comput. 2007, 3, 1120-1133.

33. Lee, H.; Venable, R.M.; MacKerell, A.D.; Pastor, R.W. Molecular dynamics studies of polyethylene oxide and polyethylene glycol: Hydrodynamic radius and shape anisotropy. Biophys. J. 2008, 95, 1590-1599.

34. Stepniewski, M.; Pasenkiewicz-Gierula, M.; Rog, T.; Danne, R.; Orlowski, A.; Karttunen, M.; Urtti, A.; Yliperttula, M.; Vuorimaa, E.; Bunker, A. Study of PEGylated lipid layers as a model for PEGylated liposome surfaces: Molecular dynamics simulation and langmuir monolayer studies. Langmuir 2011, 27, 7788-7798.

35. Bedrov, D.; Ayyagari, C.; Smith, G.D. Multiscale modeling of poly(ethylene oxide)poly(propylene oxide)-poly(ethylene oxide) triblock copolymer micelles in aqueous solution. J. Chem. Theory Comput. 2006, 2, 598-606.

36. Fischer, J.; Paschek, D.; Geiger, A.; Sadowski, G. Modeling of aqueous poly(oxyethylene) solutions: 2. Mesoscale simulations. J. Phys. Chem. B 2008, 112, 13561-13571.

37. Chen, T.; Hynninen, A.P.; Prud'homme, R.K.; Kevrekidis, I.G.; Panagiotopoulos, A.Z. Coarse-grained simulations of rapid assembly kinetics for polystyrene- $b$-poly(ethylene oxide) copolymers in aqueous solutions. J. Phys. Chem. B 2008, 112, 16357-16366.

38. Srinivas, G.; Shelley, J.C.; Nielsen, S.O.; Discher, D.E.; Klein, M.L. Simulation of diblock copolymer self-assembly, using a coarse-grain model. J. Phys. Chem. B 2004, 108, 8153-8160.

39. Srinivas, G.; Klein, M.L. Coarse-grain molecular dynamics simulations of diblock copolymer surfactants interacting with a lipid bilayer. Mol. Phys. 2004, 102, 883-889.

40. Srinivas, G.; Discher, D.E.; Klein, M.L. Self-assembly and properties of diblock copolymers by coarse-grain molecular dynamics. Nat. Mater. 2004, 3, 638-644.

41. Marrink, S.J.; Risselada, H.J.; Yefimov, S.; Tieleman, D.P.; de Vries, A.H. The martini force field: Coarse grained model for biomolecular simulations. J. Phys. Chem. B 2007, 111, 7812-7824.

42. Marrink, S.J.; de Vries, A.H.; Mark, A.E. Coarse grained model for semiquantitative lipid simulations. J. Phys. Chem. B 2004, 108, 750-760.

43. Lee, H.; de Vries, A.H.; Marrink, S.J.; Pastor, R.W. A coarse-grained model for polyethylene oxide and polyethylene glycol: Conformation and hydrodynamics. J. Phys. Chem. B 2009, 113, 13186-13194.

44. Lee, H.; Pastor, R.W. Coarse-grained model for PEGylated lipids: Effect of PEGylation on the size and shape of self-assembled structures. J. Phys. Chem. B 2011, 115, 7830-7837.

45. Lee, H.; Kim, H.R.; Larson, R.G.; Park, J.C. Effects of the size, shape, and structural transition of thermosensitive polypeptides on the stability of lipid bilayers and liposomes. Macromolecules 2012, 45, 7304-7312.

46. Rossi, G.; Fuchs, P.F.J.; Barnoud, J.; Monticelli, L. A coarse-grained martini model of polyethylene glycol and of polyoxyethylene alkyl ether surfactants. J. Phys. Chem. B 2012, 116, 14353-14362.

47. Wang, Q.; Keffer, D.J.; Nicholson, D.M. A coarse-grained model for polyethylene glycol polymer. J. Chem. Phys. 2011, 135, 214903:1-214903:10.

48. Zasloff, M. Antimicrobial peptides of multicellular organisms. Nature 2002, 415, 389-395. 
49. Matsuzaki, K. Control of cell selectivity of antimicrobial peptides. Biochim. Biophys. Acta 2009, 1788, 1687-1692.

50. Matsuzaki, K. Why and how are peptide-lipid interactions utilized for self-defense? Magainins and tachyplesins as archetypes. Biochim. Biophys. Acta 1999, 1462, 1-10.

51. Guiotto, A.; Pozzobon, M.; Canevari, M.; Manganelli, R.; Scarin, M.; Veronese, F.M. PEGylation of the antimicrobial peptide nisin A: Problems and perspectives. Farmaco 2003, 58, 45-50.

52. Mátyus, E.; Kandt, C.; Tieleman, D.P. Computer simulation of antimicrobial peptides. Curr. Med. Chem. 2007, 14, 2789-2798.

53. Rzepiela, A.J.; Sengupta, D.; Goga, N.; Marrink, S.J. Membrane poration by antimicrobial peptides combining atomistic and coarse-grained descriptions. Faraday Discuss. 2010, 144, 431-443.

54. Leontiadou, H.; Mark, A.E.; Marrink, S.J. Antimicrobial peptides in action. J. Am. Chem. Soc. 2006, 128, 12156-12161.

55. Wu, X.; Chang, H.; Mello, C.; Nagarajan, R.; Narsimhan, G. Effect of interaction with coesite silica on the conformation of cecropin $\mathrm{p} 1$ using explicit solvent molecular dynamics simulation. J. Chem. Phys. 2013, doi: 10.1063/1.4788662.

56. Han, E.; Lee, H. Effects of PEGylation on the binding interaction of magainin 2 and tachyplesin I with lipid bilayer surface. Langmuir 2013, 29, 14214-14221.

57. Lupas, A.N.; Gruber, M. The Structure of Alpha-Helical Coiled Coils. In Fibrous Proteins: Coiled-Coils, Collagen and Elastomers; Elsevier Academic Press Inc.: San Diego, CA, USA, 2005; Volume 70, pp. 37-78.

58. Woolfson, D.N. The Design of Coiled-Coil Structures and Assemblies. In Fibrous Proteins: Coiled-Coils, Collagen and Elastomers; Elsevier Academic Press Inc.: San Diego, CA, USA, 2005; Volume 70, pp. 79-112.

59. Gruber, M.; Lupas, A.N. Historical review: Another 50th anniversary-New periodicities in coiled coils. Trends Biochem. Sci. 2003, 28, 679-685.

60. Woolfson, D.N.; Ryadnov, M.G. Peptide-based fibrous biomaterials: Some things old, new and borrowed. Curr. Opin. Chem. Biol. 2006, 10, 559-567.

61. Woolfson, D.N.; Mahmoud, Z.N. More than just bare scaffolds: Towards multi-component and decorated fibrous biomaterials. Chem. Soc. Rev. 2010, 39, 3464-3479.

62. Deacon, S.P.E.; Apostolovic, B.; Carbajo, R.J.; Schott, A.K.; Beck, K.; Vicent, M.J.; Pineda-Lucena, A.; Klok, H.A.; Duncan, R. Polymer coiled-coil conjugates: Potential for development as a new class of therapeutic "molecular switch". Biomacromolecules 2011, 12, 19-27.

63. Vandermeulen, G.W.M.; Tziatzios, C.; Duncan, R.; Klok, H.A. PEG-based hybrid block copolymers containing $\alpha$-helical coiled coil peptide sequences: Control of self-assembly and preliminary biological evaluation. Macromolecules 2005, 38, 761-769.

64. Klok, H.A.; Vandermeulen, G.W.M.; Nuhn, H.; Rösler, A.; Hamley, I.W.; Castelletto, V.; $\mathrm{Xu}, \mathrm{H}$.; Sheiko, S.S. Peptide mediated formation of hierarchically organized solution and solid state polymer nanostructures. Faraday Discuss. 2005, 128, 29-41.

65. Vandermeulen, G.W.M.; Hinderberger, D.; Xu, H.; Sheiko, S.S.; Jeschke, G.; Klok, H.A. Structure and dynamics of self-assembled poly(ethylene glycol) based coiled-coil nano-objects.

Chem. Phys. Chem. 2004, 5, 488-494. 
66. Vandermeulen, G.W.M.; Tziatzios, C.; Klok, H.A. Reversible self-organization of poly(ethylene glycol)-based hybrid block copolymers mediated by a de novo four-stranded $\alpha$-helical coiled coil motif. Macromolecules 2003, 36, 4107-4114.

67. Zheng, T.; Voskuhl, J.; Versluis, F.; Zope, H.R.; Tomatsu, I.; Marsden, H.R.; Kros, A. Controlling the rate of coiled coil driven membrane fusion. Chem. Commun. 2013, 49, 3649-3651.

68. Martelli, G.; Zope, H.R.; Bròvia Capell, M.; Kros, A. Coiled-coil peptide motifs as thermoresponsive valves for mesoporous silica nanoparticles. Chem. Commun. 2013, 49, 9932-9934.

69. Tomatsu, I.; Marsden, H.R.; Rabe, M.; Versluis, F.; Zheng, T.; Zope, H.; Kros, A. Influence of PEGylation on peptide-mediated liposome fusion. J. Mater. Chem. 2011, 21, 18927-18933.

70. Robson Marsden, H.; Handgraaf, J.W.; Nudelman, F.; Sommerdijk, N.A.J.M.; Kros, A. Uniting polypeptides with sequence-designed peptides: Synthesis and assembly of poly $(\gamma$-benzyl L-glutamate)- $b$-coiled-coil peptide copolymers. J. Am. Chem. Soc. 2010, 132, 2370-2377.

71. Marsden, H.R.; Korobko, A.V.; van Leeuwen, E.N.M.; Pouget, E.M.; Veen, S.J.; Sommerdijk, N.A.J.M.; Kros, A. Noncovalent triblock copolymers based on a coiled-coil peptide motif. J. Am. Chem. Soc. 2008, 130, 9386-9393.

72. Shu, J.Y.; Lund, R.; Xu, T. Solution structural characterization of coiled-coil peptide-polymer side-conjugates. Biomacromolecules 2012, 13, 1945-1955.

73. Dong, H.; Dube, N.; Shu, J.Y.; Seo, J.W.; Mahakian, L.M.; Ferrara, K.W.; Xu, T. Long-circulating $15 \mathrm{~nm}$ micelles based on amphiphilic 3-helix peptide-PEG conjugates. ACS Nano 2012, 6, 5320-5329.

74. Shu, J.Y.; Huang, Y.J.; Tan, C.; Presley, A.D.; Chang, J.; Xu, T. Amphiphilic peptide-polymer conjugates based on the coiled-coil helix bundle. Biomacromolecules 2010, 11, 1443-1452.

75. Shu, J.Y.; Tan, C.; DeGrado, W.F.; Xu, T. New design of helix bundle peptide-polymer conjugates. Biomacromolecules 2008, 9, 2111-2117.

76. Dong, H.; Shu, J.Y.; Dube, N.; Ma, Y.; Tirrell, M.V.; Downing, K.H.; Xu, T. 3-Helix micelles stabilized by polymer springs. J. Am. Chem. Soc. 2012, 134, 11807-11814.

77. Lupas, A. Predicting coiled-coil regions in proteins. Curr. Opin. Struct. Biol. 1997, 7, 388-393.

78. Lupas, A.; van Dyke, M.; Stock, J. Predicting coiled coils from protein sequences. Science 1991, 252, 1162-1164.

79. Berger, B.; Wilson, D.B.; Wolf, E.; Tonchev, T.; Milla, M.; Kim, P.S. Predicting coiled coils by use of pairwise residue correlations. Proc. Natl. Acad. Sci. USA 1995, 92, 8259-8263.

80. Woolfson, D.N.; Alber, T. Predicting oligomerization states of coiled coils. Protein Sci. 1995, 4, 1596-1607.

81. Wolf, E.; Kim, P.S.; Berger, B. Multicoil: A program for predicting two- and three-stranded coiled coils. Protein Sci. 1997, 6, 1179-1189.

82. Walshaw, J.; Woolfson, D.N. Socket: A program for identifying and analysing coiled-coil motifs within protein structures. J. Mol. Biol. 2001, 307, 1427-1450.

83. Gruber, M.; Söding, J.; Lupas, A.N. Repper-Repeats and their periodicities in fibrous proteins. Nucleic Acids Res. 2005, 33, W239-W243. 
84. Rozzelle, J.E., Jr.; Tropsha, A.; Erickson, B.W. Rational design of a three-heptad coiled-coil protein and comparison by molecular dynamics simulation with the GCN4 coiled coil: Presence of interior three-center hydrogen bonds. Protein Sci. 1994, 3, 345-355.

85. Zhong, Q.; Jiang, Q.; Moore, P.B.; Newns, D.M.; Klein, M.L. Molecular dynamics simulation of a synthetic ion channel. Biophys. J. 1998, 74, 3-10.

86. Orzechowski, M.; Cieplak, P.; Piela, L. Theoretical calculation of the coiled-coil stability in water in the context of its possible use as a molecular rack. J. Comput. Chem. 2002, 23, 106-110.

87. Danciulescu, C.; Nick, B.; Wortmann, F.J., Structural stability of wild type and mutated $\alpha$-keratin fragments: Molecular dynamics and free energy calculations. Biomacromolecules 2004, 5, 2165-2175.

88. Missimer, J.H.; Steinmetz, M.O.; Jahnke, W.; Winkler, F.K.; van Gunsteren, W.F.; Daura, X. Molecular-dynamics simulations of $C$ - and $N$-terminal peptide derivatives of GCN4-p1 in aqueous solution. Chem. Biodivers. 2005, 2, 1086-1104.

89. Pagel, K.; Seeger, K.; Seiwert, B.; Villa, A.; Mark, A.E.; Berger, S.; Koksch, B. Advanced approaches for the characterization of a de novo designed antiparallel coiled coil peptide. Org. Biomol. Chem. 2005, 3, 1189-1194.

90. Piñeiro, Á.; Villa, A.; Vagt, T.; Koksch, B.; Mark, A.E. A molecular dynamics study of the formation, stability, and oligomerization state of two designed coiled coils: Possibilities and limitations. Biophys. J. 2005, 89, 3701-3713.

91. Kelly, E.; Privé, G.G.; Tieleman, D.P. Molecular models of lipopeptide detergents: Large coiled-coils with hydrocarbon interiors. J. Am. Chem. Soc. 2005, 127, 13446-13447.

92. Lee, H.; Larson, R.G. Prediction of the stability of coiled coils using molecular dynamics simulations. Mol. Simul. 2007, 33, 463-473.

93. Oshaben, K.M.; Salari, R.; McCaslin, D.R.; Chong, L.T.; Horne, W.S. The native GCN4 leucine-zipper domain does not uniquely specify a dimeric oligomerization state. Biochemistry 2012, 51, 9581-9591.

94. Jain, A.; Ashbaugh, H.S. Helix stabilization of poly(ethylene glycol)-peptide conjugates. Biomacromolecules 2011, 12, 2729-2734.

95. Hamed, E.; Xu, T.; Keten, S. Poly(ethylene glycol) conjugation stabilizes the secondary structure of $\alpha$-helices by reducing peptide solvent accessible surface area. Biomacromolecules 2013, 14, 4053-4060.

96. Ruiz, L.; Keten, S. Directing the self-assembly of supra-biomolecular nanotubes using entropic forces. Soft Matter 2014, 10, 851-861.

97. Majoros, I.J.; Williams, C.R.; Baker, J.R. Current dendrimer applications in cancer diagnosis and therapy. Curr. Top. Med. Chem. 2008, 8, 1165-1179.

98. Tian, W.D.; Ma, Y.Q. Theoretical and computational studies of dendrimers as delivery vectors. Chem. Soc. Rev. 2013, 42, 705-727.

99. Tu, C.K.; Chen, K.; Tian, W.D.; Ma, Y.Q. Computational investigations of a peptide-modified dendrimer interacting with lipid membranes. Macromol. Rapid Commun. 2013, 34, 1237-1242.

100. Lee, H.; Larson, R.G. Multiscale modeling of dendrimers and their interactions with bilayers and polyelectrolytes. Molecules 2009, 14, 423-438. 
101. Kelly, C.V.; Liroff, M.G.; Triplett, L.D.; Leroueil, P.R.; Mullen, D.G.; Wallace, J.M.; Meshinchi, S.; Baker, J.R.; Orr, B.G.; Holl, M.M.B. Stoichiometry and structure of poly(amidoamine) dendrimer-lipid complexes. ACS Nano 2009, 3, 1886-1896.

102. Lee, H.; Larson, R.G. Lipid bilayer curvature and pore formation induced by charged linear polymers and dendrimers: The effect of molecular shape. J. Phys. Chem. B 2008, 112, 12279-12285.

103. Lee, H.; Larson, R.G. Coarse-grained molecular dynamics studies of the concentration and size dependence of fifth- and seventh-generation pamam dendrimers on pore formation in dmpc bilayer. J. Phys. Chem. B 2008, 112, 7778-7784.

104. Lee, H.; Larson, R.G. Molecular dynamics simulations of pamam dendrimer-induced pore formation in DPPC bilayers with a coarse-grained model. J. Phys. Chem. B 2006, 110, 18204-18211.

105. Lee, H.; Baker, J.R.; Larson, R.G. Molecular dynamics studies of the size, shape, and internal structure of $0 \%$ and $90 \%$ acetylated fifth-generation polyamidoamine dendrimers in water and methanol. J. Phys. Chem. B 2006, 110, 4014-4019.

106. Lee, H.; Choi, J.S.; Larson, R.G. Molecular dynamics studies of the size and internal structure of the pamam dendrimer grafted with arginine and histidine. Macromolecules 2011, 44, 8681-8686.

107. Chen, J.M.; Hessler, J.A.; Putchakayala, K.; Panama, B.K.; Khan, D.P.; Hong, S.; Mullen, D.G.; DiMaggio, S.C.; Som, A.; Tew, G.N.; et al. Cationic nanoparticles induce nanoscale disruption in living cell plasma membranes. J. Phys. Chem. B 2009, 113, 11179-11185.

108. Leroueil, P.R.; Berry, S.A.; Duthie, K.; Han, G.; Rotello, V.M.; McNerny, D.Q.; Baker, J.R.; Orr, B.G.; Holl, M.M.B. Wide varieties of cationic nanoparticles induce defects in supported lipid bilayers. Nano Lett. 2008, 8, 420-424.

109. Kelly, C.V.; Leroueil, P.R.; Nett, E.K.; Wereszczynski, J.M.; Baker, J.R.; Orr, B.G.; Holl, M.M.B.; Andricioaei, I. Poly(amidoamine) dendrimers on lipid bilayers I: Free energy and conformation of binding. J. Phys. Chem. B 2008, 112, 9337-9345.

110. Kandasamy, S.K.; Lee, H.; Larson, R.G. Computer Simulations of Dendrimers. In Dendrimer-Based Nanomedicine; Majoros, I.J., Baker, J.R.J., Eds.; Pan Stanford Publishing: Singapore, 2008; pp. 331-354.

111. Leroueil, P.R.; Hong, S.Y.; Mecke, A.; Baker, J.R.; Orr, B.G.; Holl, M.M.B. Nanoparticle interaction with biological membranes: Does nanotechnology present a janus face? Acc. Chem. Res. 2007, 40, 335-342.

112. Hong, S.P.; Leroueil, P.R.; Janus, E.K.; Peters, J.L.; Kober, M.M.; Islam, M.T.; Orr, B.G.; Baker, J.R.; Holl, M.M.B. Interaction of polycationic polymers with supported lipid bilayers and cells: Nanoscale hole formation and enhanced membrane permeability. Bioconjugate Chem. 2006, 17, 728-734.

113. Shukla, R.; Thomas, T.P.; Peters, J.; Kotlyar, A.; Myc, A.; Baker, J.R., Jr. Tumor angiogenic vasculature targeting with pamam dendrimer-rgd conjugates. Chem. Commun. 2005, 5739-5741.

114. Patri, A.K.; Kukowska-Latallo, J.F.; Baker, J.R. Targeted drug delivery with dendrimers: Comparison of the release kinetics of covalently conjugated drug and non-covalent drug inclusion complex. Adv. Drug Deliv. Rev. 2005, 57, 2203-2214. 
115. Mecke, A.; Majoros, I.J.; Patri, A.K.; Baker, J.R.; Holl, M.M.B.; Orr, B.G. Lipid bilayer disruption by polycationic polymers: The roles of size and chemical functional group. Langmuir 2005, 21, 10348-10354.

116. Choi, Y.; Thomas, T.; Kotlyar, A.; Islam, M.T.; Baker, J.R. Synthesis and functional evaluation of DNA-assembled polyamidoamine dendrimer clusters for cancer cell-specific targeting. Chem. Biol. 2005, 12, 35-43.

117. Mecke, A.; Uppuluri, S.; Sassanella, T.M.; Lee, D.K.; Ramamoorthy, A.; Baker, J.R.; Orr, B.G.; Holl, M.M.B. Direct observation of lipid bilayer disruption by poly(amidoamine) dendrimers. Chem. Phys. Lipids 2004, 132, 3-14.

118. Mecke, A.; Lee, I.; Baker, J.R.; Holl, M.M.B.; Orr, B.G. Deformability of poly(amidoamine) dendrimers. Eur. Phys. J. E 2004, 14, 7-16.

119. Hong, S.P.; Bielinska, A.U.; Mecke, A.; Keszler, B.; Beals, J.L.; Shi, X.Y.; Balogh, L.; Orr, B.G.; Baker, J.R.; Holl, M.M.B. Interaction of poly(amidoamine) dendrimers with supported lipid bilayers and cells: Hole formation and the relation to transport. Bioconj. Chem.2004, 15, 774-782.

120. Choi, Y.S.; Mecke, A.; Orr, B.G.; Holl, M.M.B.; Baker, J.R. DNA-directed synthesis of generation 7 and 5 pamam dendrimer nanoclusters. Nano Lett. 2004, 4, 391-397.

121. Majoros, I.J.; Keszler, B.; Woehler, S.; Bull, T.; Baker, J.R. Acetylation of poly(amidoamine) dendrimers. Macromolecules 2003, 36, 5526-5529.

122. Patri, A.K.; Majoros, I.J.; Baker, J.R. Dendritic polymer macromolecular carriers for drug delivery. Curr. Opin. Chem. Biol. 2002, 6, 466-471.

123. Choi, S.K.; Myc, A.; Silpe, J.E.; Sumit, M.; Wong, P.T.; McCarthy, K.; Desai, A.M.; Thomas, T.P.; Kotlyar, A.; Holl, M.M.B.; et al. Dendrimer-based multivalent vancomycin nanoplatform for targeting the drug-resistant bacterial surface. ACS Nano 2013, 7, 214-228.

124. Zong, H.; Thomas, T.P.; Lee, K.H.; Desai, A.M.; Li, M.H.; Kotlyar, A.; Zhang, Y.; Leroueil, P.R.; Gam, J.J.; Holl, M.M.B.; et al. Bifunctional pamam dendrimer conjugates of folic acid and methotrexate with defined ratio. Biomacromolecules 2012, 13, 982-991.

125. Thomas, T.P.; Huang, B.; Choi, S.K.; Silpe, J.E.; Kotlyar, A.; Desai, A.M.; Zong, H.; Gam, J.; Joice, M.; Baker, J.R. Polyvalent dendrimer-methotrexate as a folate receptor-targeted cancer therapeutic. Mol. Pharm. 2012, 9, 2669-2676.

126. Mullen, D.G.; Desai, A.; van Dongen, M.A.; Barash, M.; Baker, J.R.; Banaszak Holl, M.M. Best practices for purification and characterization of pamam dendrimer. Macromolecules 2012 , $45,5316-5320$.

127. Lyulin, S.V.; Vattulainen, I.; Gurtovenko, A.A. Complexes comprised of charged dendrimers, linear polyelectrolytes, and counterions: Insight through coarse-grained molecular dynamics simulations. Macromolecules 2008, 41, 4961-4968.

128. Welch, P.; Muthukumar, M. Dendrimer-polyelectrolyte complexation: A model guest-host system. Macromolecules 2000, 33, 6159-6167.

129. Hedden, R.C.; Bauer, B.J. Structure and dimensions of PAMAM/PEG dendrimer-star polymers. Macromolecules 2003, 36, 1829-1835. 
130. Tanis, I.; Karatasos, K. Molecular dynamics simulations of polyamidoamine dendrimers and their complexes with linear poly(ethylene oxide) at different ph conditions: Static properties and hydrogen bonding. Phys. Chem. Chem. Phys. 2009, 11, 10017-10028.

131. Lee, H.; Larson, R.G. Molecular dynamics study of the structure and interparticle interactions of polyethylene glycol-conjugated pamam dendrimers. J. Phys. Chem. B 2009, 113, 13202-13207.

132. Lee, H.; Larson, R.G. Membrane pore formation induced by acetylated and polyethylene glycol-conjugated polyamidoamine dendrimers. J. Phys. Chem. C 2011, 115, 5316-5322.

133. Lee, H.; Larson, R.G. Effects of PEGylation on the size and internal structure of dendrimers: Self-penetration of long PEG chains into the dendrimer core. Macromolecules 2011, 44, 2291-2298.

134. Albertazzi, L.; Mickler, F.M.; Pavan, G.M.; Salomone, F.; Bardi, G.; Panniello, M.; Amir, E.; Kang, T.; Killops, K.L.; Bräuchle, C.; et al. Enhanced bioactivity of internally functionalized cationic dendrimers with PEG cores. Biomacromolecules 2012, 13, 4089-4097.

135. Karatasos, K. Self-association and complexation of the anti-cancer drug doxorubicin with PEGylated hyperbranched polyesters in an aqueous environment. J. Phys. Chem. B 2013, 117, 2564-2575.

136. Pavan, G.M.; Barducci, A.; Albertazzi, L.; Parrinello, M. Combining metadynamics simulation and experiments to characterize dendrimers in solution. Soft Matter 2013, 9, 2593-2597.

137. Bianco, A.; Kostarelos, K.; Prato, M. Applications of carbon nanotubes in drug delivery. Curr. Opin. Chem. Biol. 2005, 9, 674-679.

138. Lacerda, L.; Bianco, A.; Prato, M.; Kostarelos, K. Carbon nanotubes as nanomedicines: From toxicology to pharmacology. Adv. Drug Deliv. Rev. 2006, 58, 1460-1470.

139. Liu, Z.; Robinson, J.T.; Tabakman, S.M.; Yang, K.; Dai, H. Carbon materials for drug delivery \& cancer therapy. Mater. Today 2011, 14, 316-323.

140. Ke, P.C.; Lamm, M.H. A biophysical perspective of understanding nanoparticles at large. Phys. Chem. Chem. Phys. 2011, 13, 7273-7283.

141. Yurekli, K.; Mitchell, C.A.; Krishnamoorti, R. Small-angle neutron scattering from surfactant-assisted aqueous dispersions of carbon nanotubes. J. Am. Chem. Soc. 2004, 126, 9902-9903.

142. Matarredona, O.; Rhoads, H.; Li, Z.; Harwell, J.H.; Balzano, L.; Resasco, D.E. Dispersion of single-walled carbon nanotubes in aqueous solutions of the anionic surfactant naddbs. J. Phys. Chem. B 2003, 107, 13357-13367.

143. Qiao, R.; Ke, P.C. Lipid-carbon nanotube self-assembly in aqueous solution. J. Am. Chem. Soc. 2006, 128, 13656-13657.

144. O’Connell, M.J.; Bachilo, S.H.; Huffman, C.B.; Moore, V.C.; Strano, M.S.; Haroz, E.H.; Rialon, K.L.; Boul, P.J.; Noon, W.H.; Kittrell, C.; et al. Band gap fluorescence from individual single-walled carbon nanotubes. Science 2002, 297, 593-596.

145. Kam, N.W.S.; Liu, Z.; Dai, H. Functionalization of carbon nanotubes via cleavable disulfide bonds for efficient intracellular delivery of sirna and potent gene silencing. J. Am. Chem. Soc. 2005, 127, 12492-12493.

146. Wu, Y.; Hudson, J.S.; Lu, Q.; Moore, J.M.; Mount, A.S.; Rao, A.M.; Alexov, E.; Ke, P.C. Coating single-walled carbon nanotubes with phospholipids. J. Phys. Chem. B 2006, 110, 2475-2478. 
147. Lin, S.; Keskar, G.; Wu, Y.; Wang, X.; Mount, A.S.; Klaine, S.J.; Moore, J.M.; Rao, A.M.; Ke, P.C. Detection of phospholipid-carbon nanotube translocation using fluorescence energy transfer. Appl. Phys. Lett. 2006, doi: 10.1063/1.2360228.

148. Liu, X.; Tao, H.; Yang, K.; Zhang, S.; Lee, S.T.; Liu, Z. Optimization of surface chemistry on single-walled carbon nanotubes for in vivo photothermal ablation of tumors. Biomaterials 2011, $32,144-151$.

149. Liu, Z.; Robinson, J.T.; Sun, X.; Dai, H. PEGylated nanographene oxide for delivery of water-insoluble cancer drugs. J. Am. Chem. Soc. 2008, 130, 10876-10877.

150. Wallace, E.J.; Sansom, M.S.P. Carbon nanotube self-assembly with lipids and detergent: A molecular dynamics study. Nanotechnology 2009, 20, 045101-045101.

151. Wallace, E.J.; Sansom, M.S.P. Carbon nanotube/detergent interactions via coarse-grained molecular dynamics. Nano Lett. 2007, 7, 1923-1928.

152. Tummala, N.R.; Morrow, B.H.; Resasco, D.E.; Striolo, A. Stabilization of aqueous carbon nanotube dispersions using surfactants: Insights from molecular dynamics simulations. ACS Nano 2010, 4, 7193-7204.

153. Xu, Z.; Yang, X.; Yang, Z. A molecular simulation probing of structure and interaction for supramolecular sodium dodecyl sulfate/single-wall carbon nanotube assemblies. Nano Lett. 2010, 10, 985-991.

154. Calvaresi, M.; Dallavalle, M.; Zerbetto, F. Wrapping nanotubes with micelles, hemimicelles, and cylindrical micelles. Small 2009, 5, 2191-2198.

155. Lopez, C.F.; Nielsen, S.O.; Moore, P.B.; Klein, M.L. Understanding nature's design for a nanosyringe. Proc. Natl. Acad. Sci. USA 2004, 101, 4431-4434.

156. Nielsen, S.O.; Ensing, B.; Ortiz, V.; Moore, P.B.; Klein, M.L. Lipid bilayer perturbations around a transmembrane nanotube: A coarse grain molecular dynamics study. Biophys. J. 2005, 88, 3822-3828.

157. Lopez, C.F.; Nielsen, S.O.; Ensing, B.; Moore, P.B.; Klein, M.L. Structure and dynamics of model pore insertion into a membrane. Biophys. J. 2005, 88, 3083-3094.

158. Hofinger, S.; Melle-Franco, M.; Gallo, T.; Cantelli, A.; Calvaresi, M.; Gomes, J.A.N.F.; Zerbetto, F. A computational analysis of the insertion of carbon nanotubes into cellular membranes. Biomaterials 2011, 32, 7079-7085.

159. Makarucha, A.J.; Todorova, N.; Yarovsky, I. Nanomaterials in biological environment: A review of computer modelling studies. Eur. Biophys. J. 2011, 40, 103-115.

160. Monticelli, L.; Salonen, E.; Ke, P.C.; Vattulainen, I. Effects of carbon nanoparticles on lipid membranes: A molecular simulation perspective. Soft Matter 2009, 5, 4433-4445.

161. Shi, X.; Kong, Y.; Gao, H. Coarse grained molecular dynamics and theoretical studies of carbon nanotubes entering cell membrane. Acta Mech. Sin. 2008, 24, 161-169.

162. Kraszewski, S.; Bianco, A.; Tarek, M.; Ramseyer, C. Insertion of short amino-functionalized single-walled carbon nanotubes into phospholipid bilayer occurs by passive diffusion. PLoS ONE 2012, doi: 10.1371/journal.pone.0040703.

163. Pogodin, S.; Baulin, V.A. Can a carbon nanotube pierce through a phospholipid bilayer? ACS Nano 2010, 4, 5293-5300. 
164. Skandani, A.A.; Zeineldin, R.; Al-Haik, M. Effect of chirality and length on the penetrability of single-walled carbon nanotubes into lipid bilayer cell membranes. Langmuir 2012, 28, 7872-7879.

165. Yang, K.; Ma, Y.Q. Computer simulation of the translocation of nanoparticles with different shapes across a lipid bilayer. Nat. Nanotechnol. 2010, 5, 579-583.

166. Wallace, E.J.; Sansom, M.S.P. Blocking of carbon nanotube based nanoinjectors by lipids: A simulation study. Nano Lett. 2008, 8, 2751-2756.

167. Shi, X.; von Dem Bussche, A.; Hurt, R.H.; Kane, A.B.; Gao, H. Cell entry of one-dimensional nanomaterials occurs by tip recognition and rotation. Nat. Nanotechnol. 2011, 6, 714-719.

168. Baoukina, S.; Monticelli, L.; Tieleman, D.P. Interaction of pristine and functionalized carbon nanotubes with lipid membranes. J. Phys. Chem. B 2013, 117, 12113-12123.

169. Lee, H.; Kim, H. Self-assembly of lipids and single-walled carbon nanotubes: Effects of lipid structure and PEGylation. J. Phys. Chem. C 2012, 116, 9327-9333.

170. Lee, H. Interparticle dispersion, membrane curvature, and penetration induced by single-walled carbon nanotubes wrapped with lipids and PEGylated lipids. J. Phys. Chem. B 2013, 117, 1337-1344.

171. Lee, H. Membrane penetration and curvature induced by single-walled carbon nanotubes: The effect of diameter, length, and concentration. Phys. Chem. Chem. Phy. 2013, 15, 16334-16340.

172. Lee, H. Molecular dynamics studies of PEGylated single-walled carbon nanotubes: The effect of PEG size and grafting density. J. Phys. Chem. C 2013, 117, 26334-26341.

173. Sacchetti, C.; Motamedchaboki, K.; Magrini, A.; Palmieri, G.; Mattei, M.; Bernardini, S.; Rosato, N.; Bottini, N.; Bottini, M. Surface polyethylene glycol conformation influences the protein corona of polyethylene glycol-modified single-walled carbon nanotubes: Potential implications on biological performance. ACS Nano 2013, 7, 1974-1989.

174. De Gennes, P.G. Polymers at an interface-A simplified view. Adv. Colloid Interface Sci. 1987, 27, 189-209.

175. Di Crescenzo, A.; Aschi, M.; Fontana, A. Toward a better understanding of steric stabilization when using block copolymers as stabilizers of single-walled carbon nanotubes (SWCNTS) aqueous dispersions. Macromolecules 2012, 45, 8043-8050.

176. Aslan, S.; Määttä, J.; Haznedaroglu, B.Z.; Goodman, J.P.M.; Pfefferle, L.D.; Elimelech, M.; Pauthe, E.; Sammalkorpi, M.; van Tassel, P.R. Carbon nanotube bundling: Influence on layer-by-layer assembly and antimicrobial activity. Soft Matter 2013, 9, 2136-2144.

177. Skandani, A.A.; Al-Haik, M. Reciprocal effects of the chirality and the surface functionalization on the drug delivery permissibility of carbon nanotubes. Soft Matter 2013, 9, 11645-11649.

178. Zeineldin, R.; Al-Haik, M.; Hudson, L.G. Role of polyethylene glycol integrity in specific receptor targeting of carbon nanotubes to cancer cells. Nano Lett.2009, 9, 751-757.

(C) 2014 by the authors; licensee MDPI, Basel, Switzerland. This article is an open access article distributed under the terms and conditions of the Creative Commons Attribution license (http://creativecommons.org/licenses/by/3.0/). 